\title{
Perancangan Prototipe Aplikasi Mobile Ikatan Alumni (Studi Kasus Universitas Bina Sarana Informatika)
}

\author{
Agung Sasongko ${ }^{\text {a1 }}$, Ali Mustopa ${ }^{\text {a2 }}$, Deni Risdiansyah ${ }^{\text {a3 }}$ \\ ${ }^{a}$ Fakultas Tehnik dan Informatika, Universitas Bina Sarana Informatika PSDKU Pontianak \\ Jl. Abdurahman Saleh No.18a, Kota Pontianak \\ ${ }^{1}$ agung.ako@bsi.ac.id \\ 2alimustopa.aop@bsi.ac.id \\ ${ }^{3}$ deni.drxabsi.ac.id
}

\begin{abstract}
Abstrak
Pada penelitian ini membahasa mengenai aplikasi yang diperuntukkan kepada Alumni pada perguruan tinggi Universitas Bina Sarana Informatika untuk menyebarluaskan informasi dari perguruan tinggi maupun mengumpulkan informasi dari alumni. Aplikasi dikembangkan berbasis mobile. Pengembangan aplikasi dilakukan dengan metode prototipe dengan cara mengumpulkan kebutuhan fungsional sistem dari pengalaman alumni serta komponen instrumen kebutuhan informasi yang berasal dari perguruan tinggi. Hasil analisa kebutuhan fungsional dilanjutkan dengan pembuatan desain Usecase dan deployment diagram. Komponen sistem yang dibuat terdari 5 komponen, yaitu: 1 . Komponen informasi lowongan kerja dan informasi wirausaha, 2. Komponen rekam riwayat pekerjaan dan penghasilan, 3. Komponen kelola profile diri, 4. Komponen forum percakapan, 5. Komponen pengisian tracer study. Desain rancangan penelitian berdasarkan 5 komponen yang diperlukan menghasilkan 14 rancangan tampilan, yaitu: racangan tampilan Login, Beranda, Pengisian Tracer Study, BSI News, Career dan Enterpreneur News, Forum, Form kirim forum, Daftar Alumni, Daftar Lowongan Kerja, Kegiatan BCC, Profile Diri, daftar riwayat pengalaman kerja, form pengalaman kerja, dan sunting profile diri.
\end{abstract}

$\underline{\text { Kata kunci: aplikasi mobile, alumni, perguruan tinggi }}$

\section{Designing an Alumni Association Mobile Application Prototype (Case Study of Bina Sarana Informatika University)}

\begin{abstract}
This research discusses applications that are intended for alumni at Bina Sarana Informatics University colleges to disseminate information from universities and collect information from alumni. The application is developed on a mobile basis. Application development is carried out by the prototype method by collecting system functional requirements from the alumni experience as well as the information needs instrument components that come from tertiary institutions. The results of the functional requirements analysis are continued with the creation of a Usecase design and deployment diagram. The components of the system are made up of 5 components, namely: 1. Information components for job vacancies and entrepreneurial information, 2. Components for recording work history and income, 3. Components of managing personal profiles, 4. Components of conversation forums, 5. Components of filling out a tracer study. The research design design is based on the 5 required components to produce 14 display designs, namely: Login, Home, Tracer Study Filling, BSI News, Career and Entrepreneur News, Forums, Forum Submission Forms, Alumni List, Job Vacancies, BCC Activities, Profile Personal, list work experience history, work experience form, and edit your profile.
\end{abstract}

Keywords: mobile applications, alumni, colleges

\section{Pendahuluan}

Alumni merupakan salah satu bagian yang tidak terpisahkan pada perguruan tinggi. Alumni sebagai cerminan lulusan dari sebuah perguruan tinggi perlu diperhatikan rekam jejak pekerjaannya pasca kelulusannya. Selain mendapatkan riwayat pekerjaan, perlu informasi berupa umpan balik dari para-alumni untuk mengetahui apakah kurikulum pada program studi di perguruan tinggi sudah sesuai dengan dunia industri maupun dunia usaha.

Menjaga komunikasi antar perguruan tinggi dan alumni yang jumlahnya banyak dan jangkauannya yang tidak dapat diukur, tentu bukan perkara mudah bila 
dilakukan secara konvensional. Memanfaatkan teknologi informasi sudah menjadi bagian yang tidak terpisahkan pada saat ini. Hadirnya perangkat cerdas telepon seluler yang lumrah digunakan sebagian banyak orang membuka kesempatan yang tinggi bagi perguruan tinggi untuk selalu terhubung ke lulusannya melalui aplikasi berbasis perangkat seluler pintar. Komunikasi melalui SMS maupun telepon langsung walau bisa dilakukan, tentu membutuhkan waktu yang sangat banyak untuk dapat mengetahui kondisi rekam jejak karir semua alumni. Melalui kebiasan penggunaan piranti lunak pada perangkat cerdas seluler saat ini bagi kebanyakan orang, maka sangat dimungkinkan untuk mengumpulkan informasi alumni dengan mengisikan secara mandiri rekam jejak karir alumni melalui piranti lunak yang disediakan oleh perguruan tinggi kepada alumni.

\section{TINJAUAN PUSTAKA}

\section{A. Mobile Application}

Aplikasi perangkat berpindah atau bahasa Inggrisnya Mobile Application adalah merupakah piranti lunak yang dijalankan pada piranti keras yang memiliki sifat layanan bergerak [1]. Pada dasarnya aplikasi mobile dikembangkan pada lapisan kerangka kerja, sedangkan aplikasi pada umumnya langsung berjalan pada level sistem operasi [2]. Perbedaan mendasar antara aplikasi dengan aplikasi mobile adalah aplikasi mobile dikembangkan di dalam framework, sedangkan aplikasi pada umumnya berjalan secara langsung di Sistem Operasi [3].

\section{B. Android}

Android merupakan sistem operasi berupa lapisanlapisan yang terdiri dari sistem operasi berbasis Linux, Android Runtime dan Application Framework [4]. Arsitektur android berupa 4 lapisan [5] seperti terlihat pada Gambar 1, yaitu: Lapisan 1 adalah kernel Linux sebagai lapisan yang paling dekat dengan mesin, lapisan ini mengatur perangkat keras. Lapisan 2 merupakan Libraries dan Android Runtime, lapisan ini terdiri dari pustaka-pustaka untuk mengelola perangkat keras serta Android Runtime sebagai inti dari Sistem Operasi Android yang menggunakan Virtual Dalvik Machine. Lapisan 3 adalah Application Framework, merupakan kerangka kerja aplikasi-aplikasi yang akan berjalan diatasnya, dan Lapisan 4 adalah segala aplikasi yang berjalan di Android.

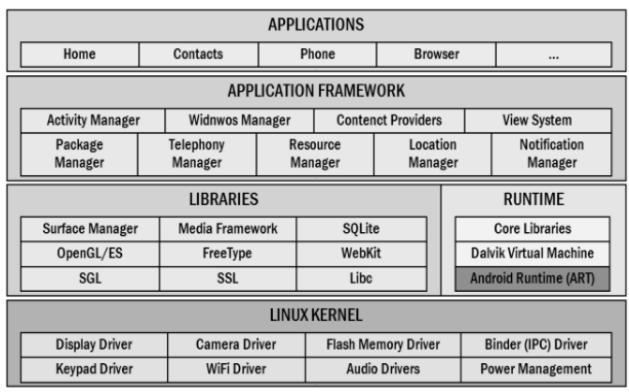

(Sumber : Khan \& Shahzad, 2016)

Gambar 1. Arsitektur Android

\section{Ikatan Alumni}

Ikatatan alumni merupakan sarana bagi para alumnus untuk dapat saling memberikan kontribusi sesama almamater untuk membangun jaringan relasi yang lebih luas diantara alumni serta menjadi bagian terpenting bagi sekolah / program studi dalam mendapatkan umpan balik lulusan di dunia kerja ataupun di dunia usaha [6]. Bagi perguruan tinggi, ikatan alumni merupakan sarana untuk menjaga eksistensi nama baik perguruan tinggi serta sebagai masukan untuk pengembangan program studi yang lebih berdaya saing.

\section{Aplikasi Mobile Alumni}

Dikutip jurnal yang ditulis oleh Kirana dan Wahdaniyah pada Jurnal Jepin berjudul "Implementasi Aplikasi Alumni berbasis Mobile Application" mereka membuat fitur aplikasi alumni yang terdiri dari fitur obrolan, fitur kegiatan alumni, fitur lowongan kerja, dan fitur personalisasi profile [7]. Begitu juga jurnal yang ditulis oleh Lukman dan Oktariandi yang berjudul "Perancangan Sistem Tracer Alumni Pada STMIK Musi Rawas Berbasis Web Mobile”, mereka mendesain aplikasi mobile selain fitur lowongan kerja juga menambahkan fitur Tracer study atau pelacakan mahasiswa setelah menjadi alumni. Tracer Study merupakan upaya untuk mengetahui aktifitas maupun keberadaan alumni pasca lulus dari perguruan tinggi [8]. Hal ini dimaksudkan untuk mengetahui apakah luaran dari program studi dari perguruan tinggi telah tepat sasaran sesuai kurikulum yang diterapkan bagi mahasiswa saat menjalankan studinya [9]. Fasilitas ini diperlukan bagi perguruan tinggi untuk evaluasi program studi serta kepentingan Akreditasi.

\section{E. RestAPI}

Layanan komunikasi data pada gaya arsitektur API (Application Programming Interface) yang menggunakan permintaan HTTP untuk akses dan menggunakan data. Metode permintaan HTTP yang dapat digunakan seperti GET, POST, DELETE, dan PUT yang menunjukkan permintaan untuk membaca data, mengisi data, hapus data dan ubah data [10]. Format data yang didukung pada RestAPI seperti JSON maupun XML, namun pada penelitian ini penulis menggunakan format JSON.

\section{F. Framework Aplikasi Mobile Multi-Platform}

Kerangka kerja (framework) Aplikasi Mobile MultiPlatform merupakan rangkaian software yang bisa dijalankan di mobile operating system yang berbeda-beda seperti Android, iOS dan Windows Phone [11]. Transofrmasi pencatatan kehadiran untuk menekan upaya manipulasi dapat diupayakan dari berbasis web ke aplikasi berbasis telepon pintar. Hasil data yang dikutip dari katadata.co, menunjukkan jumlah pengguna telepon pintar di Indonesia tiap tahunnya mengalami peningkatan, mulai dari tahun 2016 yang tercatat 65.2 juta pengguna, 2017 tercatat 74,9 juta, tahun 2018 tercatat 83.5 juta dan di tahun 2019 tercatat 92 juta pengguna telepon pintar [12]. Dikutip pula dari data yang dikeluarkan oleh StatCounter 
per Mei 2021, share market jumlah pengguna telepon genggam cerdas di indonesia adalah pengguna Android $91.44 \%$ dan iOS $8.37 \%$, dan sisanya $0.01 \%$ [13]. Dari data diatas menunjukkan bahwa jumlah pemilik telepon pintar telah banyak, dan semua karyawan telah memilikinya. Dengan cara presensi dilakukan pada perangkat telepon pintar masing-masing karyawan, sehingga dari sisi penerapan biaya yang dikeluarkan tidak akan menjadi besar. Dari sisi teknologi, berdasarkan jumlah pengguna perangkat cerdas dan sistem operasinya pengembangan aplikasi yang lebih dominan yaitu berbasis Android dan IOS [2].

\section{PEMBAHASAN}

Pada penelitian ini proses pengembangan perangkat lunak menggunakan pendekatan purwarupa (prototype). Metode purwarupa dapat digunakan baik pada sistem kecil maupun sistem yang besar, hal ini bertujuan untuk memudahkan langkah pengembangan awal bagi calon pengguna untuk lebih mengetahui sistem seperti apa yang diinginkan [14]. Proses pengembangan sistem menggunakan metode purwarupa ini terdiri dari:

1) Pengumpulan Kebutuhan

2) Proses Desain antar muka / perancangan

3) Membuat purwarupa

4) Evaluasi dan Perbaikan

Pada tahapan 1 merupakan tahapan paling awal dari pengembangan aplikasi yang menjadi pondasi menentukan keberhasilan mengenai suatu informasi yang dihasilkan nantinya [15]. Pada tahapan 2, 3 dan 4 akan mengalami iterasi seiring dengan hasil evaluasi yang didapatkan dari calon pengguna.

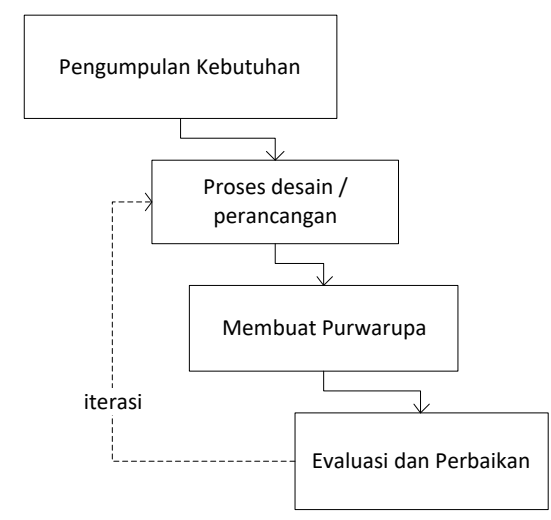

Sumber: (Purnomo, 2017)

Gambar 2. Tahapan metode purwarupa

\section{A. Pengumpulan Kebutuhan}

Tahapan ini penulis mengumpulkan data berupa kebutuhan baik fungsionalitas sistem dan non fungsionalitas.

1) Kebutuhan Fungsional:

a. Aplikasi harus dapat mengidentifikasi pengguna, yaitu alumni berdasarkan nomor induk mahasiswa (NIM) dan kata sandi standar yaitu tanggal lahir dengan format (YYYY-MM-dd).

b. Aplikasi memiliki fitur untuk pengisian Tracer Study Alumni yang terintegrasi dengan sistem informasi Alumni.

c. Aplikasi terhubung dengan website BSI News sebagai portal yang menyajikan berita seputra kampus BSI.

d. Aplikasi dapat menampilkan daftar namanama alumni agar alumni dapat menjalin jaringan sesama alumni Universitas Bina Sarana Informatika.

e. Aplikasi memiliki fitur untuk merekam pengalaman kerja alumni.

f. Aplikasi harus dapat terintegrasi ke sistem BSI Career Center (career.bsi.ac.id) untuk menampilkan informasi kegiatan Career Center, Berita seputar lowongan kerja dan berita tentang karir.

g. Aplikasi harus dapat terintegrasi ke sistem BSI Enterpreneur Center (bec.bsi.ac.id). untuk menampilkan berita seputar kewirausahaan yang di kelola oleh BSI Enterpreneur Center (BCC).

h. Aplikasi harus memiliki forum sebagai media berbagi informasi antar alumni.

i. Aplikasi harus memiliki fitur sunting profile diri alumni untuk memperbaharui informasi seperti email, nomor handphone, alamat rumah, dan pengalaman kerja.

2) Kebutuhan non-fungsional

a. Mesin server api.bsi.ac.id dengan menggunakan OS Centos 7 sebagai penyedia RestAPI yang terhubung secara online agar dapat diakses oleh aplikasi mobile.

b. Web Service menggunakan platform PHP 7.4.

c. Koneksi basisdata menggunakan driver PDO MySQL dan terhubung ke basisdata 4 mesin server, yaitu: alumni.bsi.ac.id, bec.bsi.ac.id, news.bsi.ac.id dan career.bsi.ac.id.

\section{B. Rancangan Sistem dan Antar Muka}

1) Use Case Diagram

Sumber: (hasil penelitian)

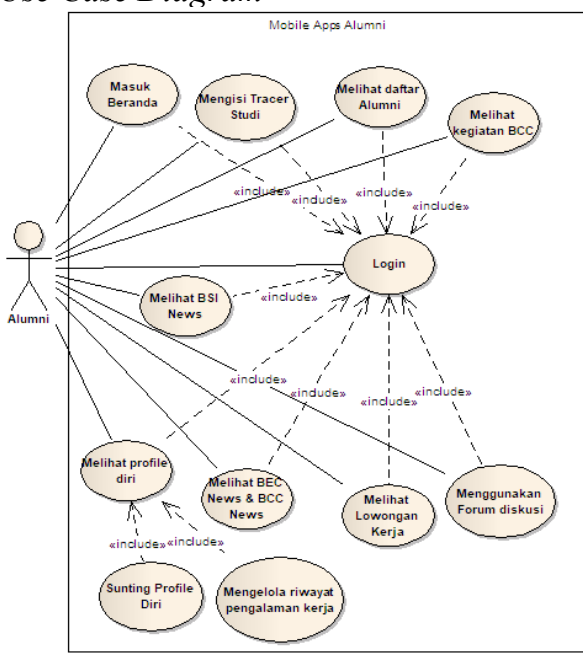

Gambar 3. Use Case Diagram Aplikasi Mobile Ikatan Alumni 
Pada diagram diatas terdapat 12 use case. Setiap usecase selain login hanya dapat diakses oleh Alumni sebagai aktor apabila aktor telah melakukan login terlebih dahulu. Alumni sebagai aktor untuk bisa menggunakan aplikasi adalah mahasiswa yang telah berstatus lulus dari sistem informasi akademik yang ada di Universitas Bina Sarana Informatika.

\section{2) Deployment Diagram}

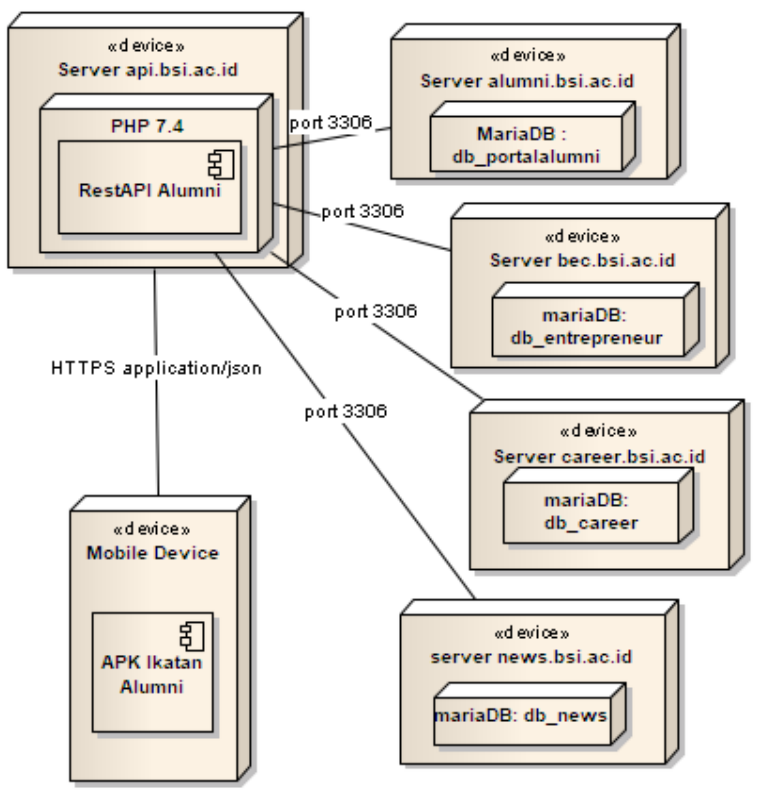

Sumber : (Hasil Penelitian)

Gambar 4. Deployment Diagram Server RestAPI

Diployment diagram diatas menunjukkan bahwa server api.bsi.ac.id sebagai penyedia konten aplikasi mobile ikatan alumni terhubung ke 4 mesin server yang berbeda, yaitu mesin server: news.bsi.ac.id, career.bsi.ac.id, bec.bsi.ac.id dan alumni.bsi.ac.id. Integrasi sistem melalui hubungan langsung koneksi ke basis data, namun antara aplikasi mobile tidak boleh terhubung langsung ke database tiap-tiap server. Aplikasi mobile mendapatkan konten data berdasarkan olahan data yang disediakan oleh server api.bsi.ac.id dalam format data JSON pada protokol HTTPS.

\section{3) Rancangan Antar Muka}

Perancangan purwarupa yang digunakan pada penelitian ini menggunakan aplikasi AdobeXD.

a. Login

Login digunakan untuk identifikasi pengguna. Masukkannnya berupa NIM alumni dan tanggal lahir alumni.

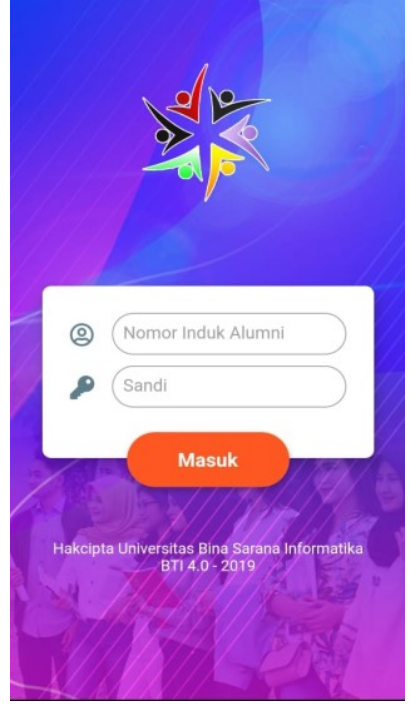

Gambar 5. Desain Login

b. Beranda

Beranda sebagai tampilan yang pertama kali muncul setelah alumni berhasil melakukan Login.

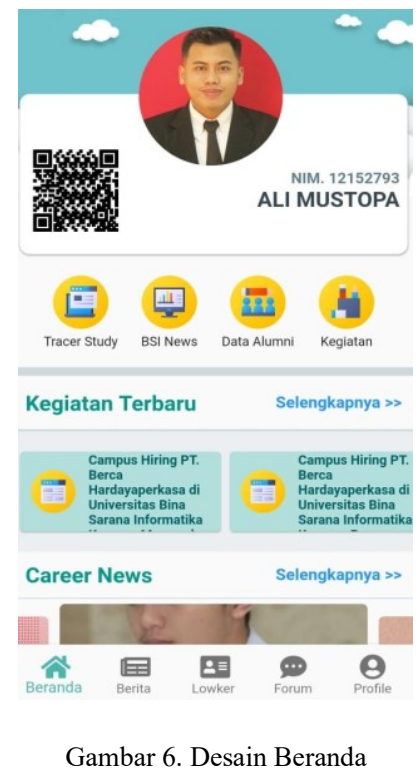

c. Tracer Study

Sistem tracer study telah ada di alumni.bsi.ac.id. Pada aplikasi mobile, sistem melakukan embeded laman tracer study yang ada di alumni.bsi.ac.id. 


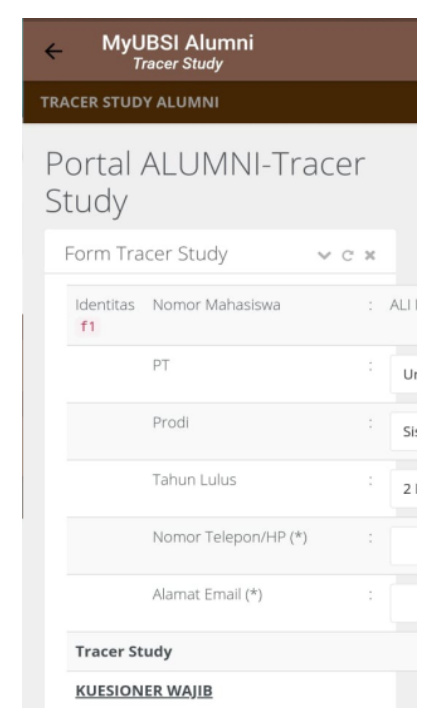

Gambar 7. Desain Laman Tracer Study

d. Daftar Alumni

Daftar alumni menampilkan alumni Universitas Bina Sarana Informatika, agar tiap alumni juga bisa mengetahui nama-nama alumni yang lain.

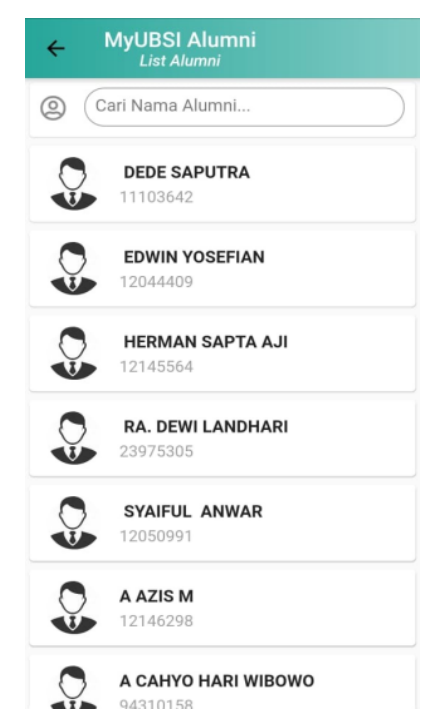

Gambar 8. Desain Daftar Alumni

e. Kegiatan BSI Career Center

Kegiatan BCC adalah informasi yang biasanya diselenggarakan oleh BCC agar diharapkan dapat diikuti oleh mahasiswa maupun alumni. Informasi kegiatan berupa nama kegiatan, tempat kegiatan dan waktu kegiatan.

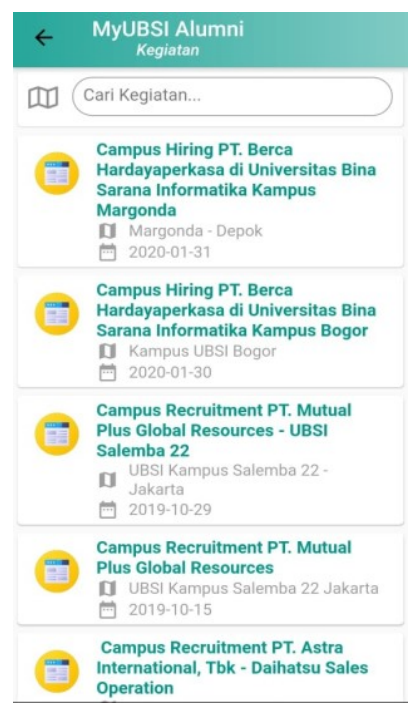

Gambar 9. Desain Informasi Kegiatan

\section{f. BSI News}

Tampilan ini menampilkan gambar dan judul berita-berita yang ada di website news.bsi.ac.id. Ini ditujukan juga kepada alumni agar alumni tetap terhubung dengan berita yang ada di Universitas Bina Sarana Informatika.

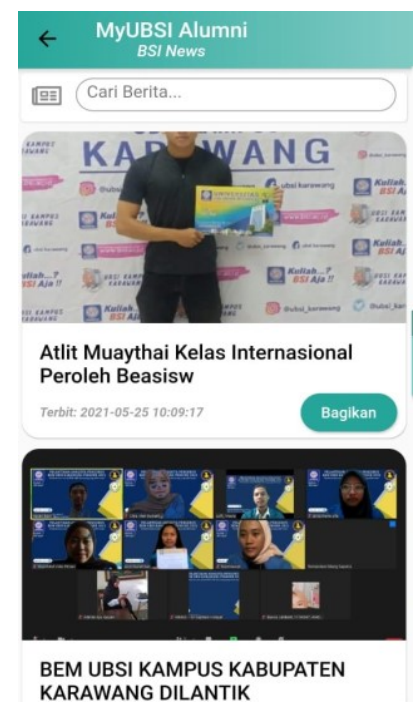

Gambar 10. Desain tampilan BSI News

g. Enterpreneur \& Career News

Berita seputar wirausaha dan pekerjaan yang dikelola oleh BEC dan BCC harus dapat diketahui oleh alumni. Apakah alumni akan memilih sebagai pengusaha atau karyawan. Informasi selalu diberikan pada bagian ini. 


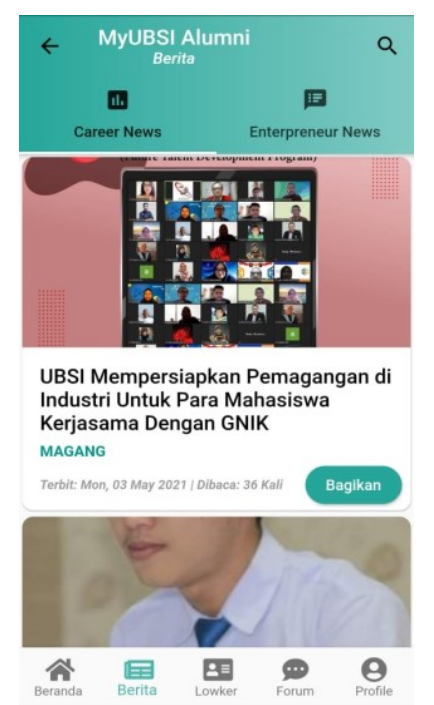

Gambar 11. Desain Career News dan Enterpreneur News

\section{h. Lowongan Kerja}

Informasi lowongan kerja bagi alumni yang belum mendapatkan pekerjaan dapat diketahui melalui informasi lowongan kerja yang selalu dikelola oleh BSI Career Center. Tampilan yang disajikan berupa gambar, nama posisi pekerjaan, nama perusahaan, nama kota perusahaan dan tanggal pembukaan lowongan kerja.

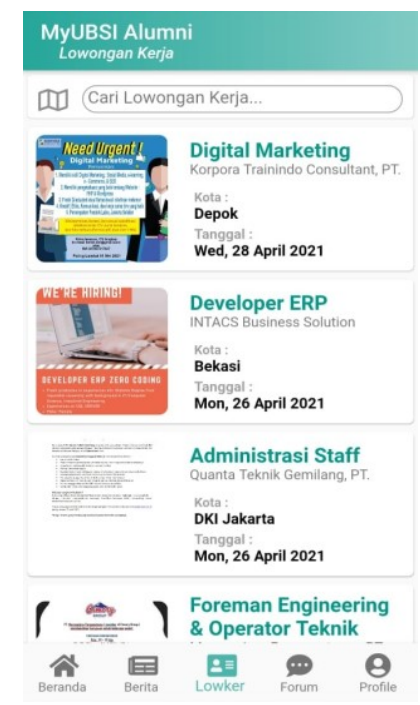

Gambar 12. Desain Tampilan Lowongan Kerja

\section{i. Forum}

Forum ditujukan kepada antar alumni agar dapat saling berkomunikasi secara tertulis dan bisa menggunakan media gambar. Media ini dapat dimanfaatkan bagi alumni untuk memberikan informasi, bertanya maupun berbagi lowongan kerja. Desain yang ditampilkan berupa identitas pengirim, tanggal kiriman, gambar yang dilampirkan, serta judul isi forum yang dikirim. Pengguna lain dapat memberikan komentar setiap kiriman melalui forum.

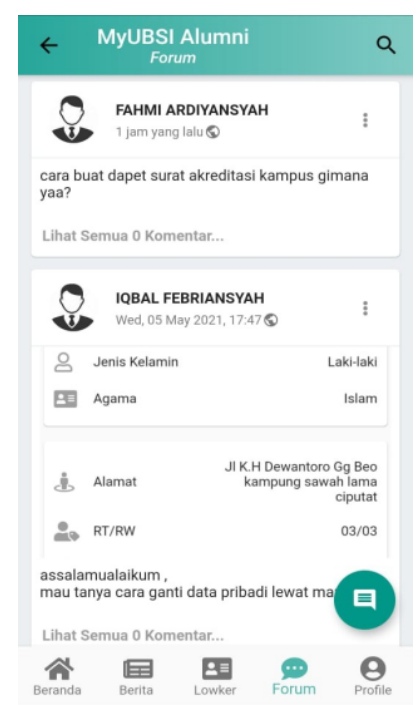

Gambar 13. Desain Tampilan Forum

\section{j. Form Kirim Forum}

Form pengiriman ke forum digunakan alumni untuk mengirimkan informasi, pertanyaan maupun diskusi ke bagian forum agar dapat diketahui maupun di komentari oleh alumni yang lain.

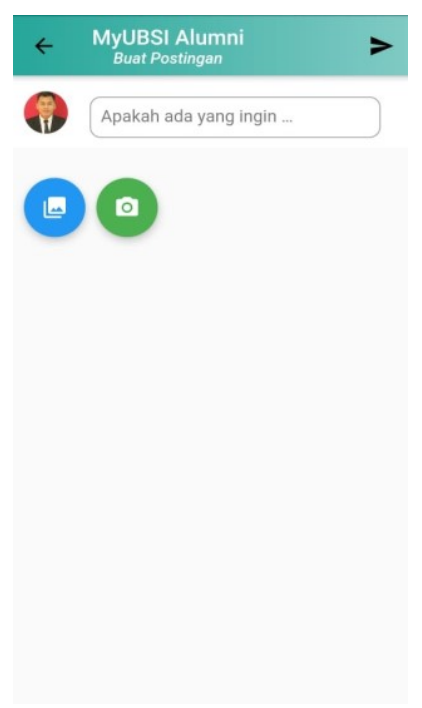

Gambar 14. Desain Form Kiriman Forum

k. Profile diri

Profile diri ditujukan kepada alumni untuk melihat data diri yang sedang login menggunakan aplikasi. 


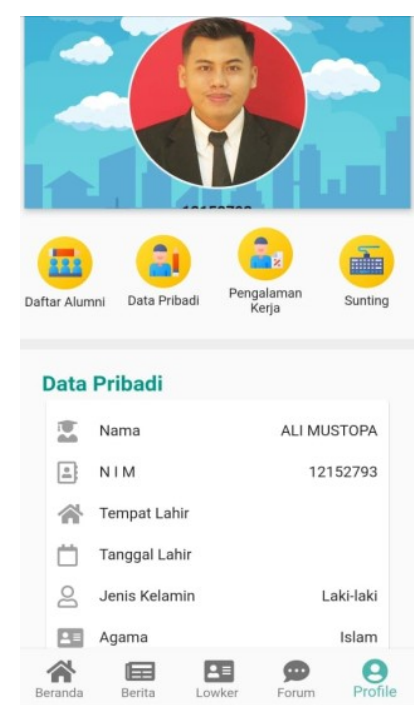

Gambar 15. Desain tampilan Profile Diri.

1. Riwayat Pengalaman Kerja

Riwaya pengalaman kerja untuk diisikan oleh alumni yang dapat digunakan oleh perguruan tinggi mendata alumni sudah bekerja dimana saja dan berapa penghasilannya. Pengguna dapat menambahkan riwayat pengalaman kerja dengan menekan tombol $(+)$.

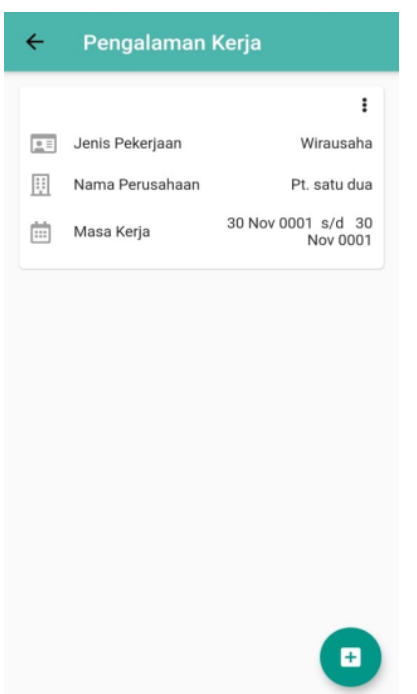

Gambar 16. Desain Riwayat Pengalaman Kerja

m. Form Pengalaman Kerja

Form pengalaman kerja digunakan alumni untuk mengisikan pengalaman kerja, berupa: Jenis Pekerjaan, bidang, jabatan, nama perusahaan, tanggal mulai bekerja, jika sudah keluar diisikan tanggal selesai. Serta penghasilan rata-rata bulanan.

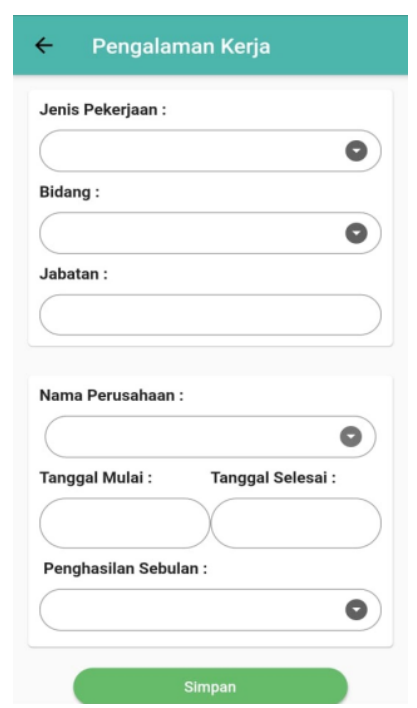

Gambar 17. Desain Form Pengalaman Kerja

n. Sunting Profile diri.

Sunting profile ditujukan kepada alumni untuk memperbaharui data miliknya, seperti foto, alamat, email maupun nomor hp.

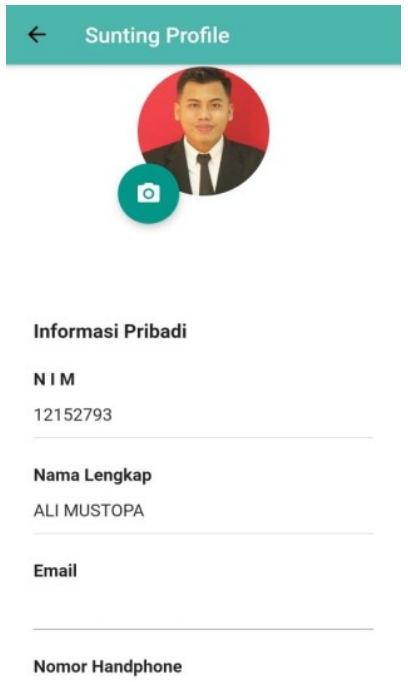

Gambar 18. Desain Tampilan Sunting Profile Diri.

\section{KESIMPULAN}

Hasil penelitian ini menghasilkan rancangan tampilan yang diperlukan untuk pengembangan aplikasi mobile Ikatan Alumni Universitas Bina Sarana Informatika (IKA UBSI). Hasil pengumpulan kebutuhan yang telah dilakukan didapat 9 kebutuhan fungsional. Kebutuhan fungsional yang disimpulkan yaitu data alumni berdasarkan dari data yang sudah ada di sistem informasi akademik Universitas Bina Sarana Informatika (UBSI). Alumni otomatis terdaftar bila memang telah menyelesaikan studinya. Sistem alumni, kewirausahaan maupun karir yang ada di UBSI sebagai sistem yang telah ada sebelumnya harus dilakukan integrasi agar data tidak tumpang tindih. Hasil analisis kebutuhan non-fungsional 
server yang diperlukan sebagai penyedia kontan adalah mesin server yang harus terhubung ke server alumni.bsi.ac.id, bec.bsi.ac.id, career.bsi.ac.id dan news.bsi.ac.id. Hal ini bertujuan agar konten yang disajikan di aplikasi mobile ikatan alumni terintegrasi ke 4 sistem yang eksisting.

\section{SARAN}

Hasil rancangan prototipe yang telah dilakukan ini perlu dilakukan penerapan untuk dibangunnya aplikasi mobile Ikatan Alumni di UBSI. Pemilihan platform IDE pengembangan aplikasi mobile yang memungkinkan dapat diterapkan untuk diproduksi ke platform Android maupun iOS seperti Flutter dapat dipertimbangkan untuk digunakan pada pembuatan aplikasi ini. Karena pengguna perangkat mobile bukan hanya Android, namun pengguna iOS juga harus diperhatikan agar dapat menggunakan aplikasi yang akan dikembangkan.

Pemilihan framework untuk aplikasi RestAPI juga menjadi perhatian agar proses yang bekerja dapat optimal memberikan layanan data ke client. Framework yang kurang optimal akan mengakibatkan kinerja server menjadi menurun sehingga layanan ke client akan menurun.

\section{UCAPAN TERIMA KASIH}

Terima kasih kepada Universitas Bina Sarana Informatika (UBSI) yang telah mendukung penuh selesainya penelitian ini, serta Biro Teknologi Informasi UBSI yang telah memberikan informasi infrastruktur server yang sangat berarti pada perancangan prototipe penerapan aplikasi mobile Ikatan Alumni.

\section{DAFTAR PUSTAKA}

[1] F. Sari, Metode Dalam Pengambilan Keputusan. Yogyakarta: Budi Utama, 2018.

[2] A. Sasongko, M. S. Maulana, and L. Latifah, "Presensi Karyawan Berbasis Aplikasi Mobile Dengan Filter Jaringan Intranet Dan Imei," Sistemasi, vol. 9, no. 1, p. 92, 2020, doi: 10.32520/stmsi.v9i1.592.

[3] A. Sasongko and R. Adwiya, "Perancangan Prototipe Aplikasi Mobile Tadzkirah," J. Edukasi Penelit. Inform., vol. 4, no. 2, pp. 197-203, 2018.

[4] A. Sasongko, "Integrasi Data Website Students.BSI.AC.ID Untuk Mobile Info Kampus berbasis Android menggunakan Ekstraksi HTML," J. Ilmu Pengetah. dan Teknol. Komput., vol. 2, no. 2, pp. 146-155, 2017, [Online]. Available:

https://scholar.google.co.id/citations?user=OuivAEkAAAAJ\& $\mathrm{hl}=\mathrm{id} \& \mathrm{oi}=\mathrm{ao} \# \mathrm{~d}=\mathrm{gs}$ md cita-

$\mathrm{d} \& \mathrm{p}=\& \mathrm{u}=\% 2 \mathrm{Fcitations} \% 3 \mathrm{Fview}$-op $\% 3$ Dview_citation $\% 26 \mathrm{hl}$ \%3Did\%26user\%3DOuivAEkAAAAJ\%26citation_for_view\% 3DOuivAEkAAAAJ\%3ATyk-4Ss8FVUC\%26tzom\%3D-420.

[5] J. Khan and S. Shahzad, "Android Architecture and Related Security Risks," Asian J. Technol. Manag. Res., vol. 05, no. March, pp. 2249-892, 2016

[6] Y. Indka, "Pentingnya Ikatan Alumni Bagi Sebuah Intansi Pendidikan," kumparan.com, 2018.

[7] C. Kirana and R. Wahdaniyah, "Implementasi Aplikasi Alumni Berbasis Mobile Application," J. Edukasi Penelit. Inform., vol. 4, no. 2, pp. 179-183, 2018.

[8] L. Hakim et al., "PERANCANGAN SISTEM TRACER ALUMNI PADA STMIK MUSI RAWAS BERBASIS WEB MOBILE," vol. 2, no. 2, pp. 108-116, 2017.

[9] I. Mohidin, S. Suleman, A. Asep, and A. L. Belakang,
"Rancang Bangun Aplikasi Tracer Study Alumni Kampus Politeknik Gorontalo Berbasis Mobile," J. Sist. Inf. Musirawas, vol. 4, no. 1, pp. 18-29, 2019, doi:

https://doi.org/10.32767/jusim.v2i2.99.

[10] A. S. Gillis, "DEFINITION REST API (RESTful API)," SearchApp Architecture, 2020. .

[11] P. Dewanti and P. A. G. Permana, "Pengembangan Aplikasi Hybrid Menggunakan Ionic 2 Framework dan Angular 2," EProceedings KNS\&I STIKOM Bali, pp. 396-400, 2017, [Online]. Available: http://knsi.stikom-

bali.ac.id/index.php/eproceedings/article/view/73\%0Ahttp://fil es/136/Pengembangan Aplikasi Hybrid Menggunakan Ionic 2 Framework dan Angular 2.pdf\%0Ahttp://files/134/73.html.

[12] Databoks.co.id, "Pengguna Smartphone di Indonesia 20162019," Katadata.co.id, 2019.

https://databoks.katadata.co.id/datapublish/2016/08/08/penggu na-smartphone-di-indonesia-2016-2019. [Accessed: 28-Juni2021]

[13] statcounter.com, "Mobile Operating System Market Share Indonesia," gs.statcounter.com, 2021.

https://gs.statcounter.com/os-market-share/mobile/worldwide. [Accessed: 28-Juni-2021]

[14] D. Purnomo, "Model Prototyping Pada Pengembangan Sistem Informasi," J. Inform. Merdeka Pasuruan, vol. 2, no. 2, pp. 54-61, 2017.

[15] D. Risdiansyah, A. Sasongko, and R. C. Verera

"Pengembangan Permainan Edukasi Untuk Penyuluhan Kesehatan Jajanan Pada Anak Sekolah Dasar Berbasis Mobile," J. Inform. Kaputama, vol. 4, no. 1, pp. 40-47, 2020. 